Diphenylether-modified 1,2-diamines with improved drug properties for development against

\title{
Mycobacterium tuberculosis
}

Marie H. Foss ${ }^{1}$, Sovitj Pou ${ }^{2}$, Patrick M. Davidson ${ }^{1}$, Jennifer L. Dunaj ${ }^{1}$, Rolf W. Winter ${ }^{2}$, Sovijja Pou², Meredith

H. Licon ${ }^{1}$, Julia K. Doh ${ }^{1}$, Yuexin Li $^{2}$, Jane X. Kelly ${ }^{2}$, Rozalia A. Dodean², Dennis R. Koop ${ }^{3}$, Michael K. Riscoe ${ }^{1,2}$, Georgiana E. Purdy ${ }^{1 *}$

1. Department of Molecular Microbiology \& Immunology, Oregon Health \& Science University, 3181 SW Sam Jackson Park Road, Portland, OR, 97239.

2. Portland VA Medical Center, 3710 SW US Veterans Hospital Road, Portland, OR, 97239.

3. Department of Physiology and Pharmacology, Oregon Health \& Science University, 3181 SW Sam Jackson Park Road, Portland, OR, 97239.

Table of Contents:

$\begin{array}{ll}\text { Supplemental Methods } & \text { S2 }\end{array}$

Table S1 - MICs of bis-adamantyl derivatives and TBL-140 against Mtb H37Rv S8

Figure S1 - Synthesis scheme for the different di-adamantane amines S9

Figure S2 - Synthesis scheme for $N^{1}$-adamantan-2-yl- $N^{2}-(4-(4-$

(trifluoromethoxy)phenoxy)benzyl)ethane-1,2-diamine 8 (TBL-140) S10

Figure S3 - Ramachandran plot of MmpL3 structure model S11

Figure S4 - Effect of SQ109 on $\Delta \Psi$ and $\Delta \mathrm{pH}$ in $M$. bovis BCG S12

$\begin{array}{ll}\text { Supplemental References } & \text { S13 }\end{array}$ 


\section{Supplemental Methods}

Chemicals and analytical methods. Unless otherwise stated all chemicals and reagents were from SigmaAldrich Chemical Company in St. Louis, MO (USA) or Combi-Blocks in San Diego (CA) and were used as received. N-bromosuccinimide (NBS) was from Sigma-Aldrich Chemical Company in St. Louis, MO (USA) and was purified according to Armarego and Lin Chai ${ }^{1}$. GC-MS spectra were obtained using a Hewlett-Packard HP5890 series II gas chromatograph $\left(30 \mathrm{~m}\right.$, DBS column set at $200{ }^{\circ} \mathrm{C}$ for $2 \mathrm{~min}$, then at $30^{\circ} \mathrm{C} / \mathrm{min}$ to $300{ }^{\circ} \mathrm{C}$, inlet temperature set at $250^{\circ} \mathrm{C}$ ) with a HP5970 mass-selective detector operating at $70 \mathrm{eV}$. Flash column chromatography separations were performed using an automated flash chromatography Isolera One from Biotage, Uppsala, Sweden. ${ }^{1} \mathrm{H}-\mathrm{NMR}$ spectra were obtained using a Bruker AMX-400 NMR spectrometer operating at $400.14 \mathrm{MHz}$ in $\mathrm{CDCl}_{3}$ unless otherwise stated. The raw NMR data were analyzed using iNMR Spectrum Analyst software. ${ }^{1} \mathrm{H}$-Chemical shifts were reported in parts million units $(\mathrm{ppm}),(\delta)$ relative to either tetramethylsilane (TMS) as internal standard or the residual proton at $7.26 \mathrm{ppm}$ in the deuterated $\mathrm{CDCl}_{3} . \mathrm{J}$ coupling constants values are in Hertz $(\mathrm{Hz})$. Mass spectra data were acquired using a high-resolution $(30,000)$ Thermo LTQ-Orbitrap Discovery hybrid mass spectrometry instrument (San Jose, CA) equipped with an electrospray ionization source operating in the positive or negative mode. The Orbitrap was externally calibrated prior to data acquisition allowing accurate mass measurements for $[\mathrm{M}+\mathrm{H}]^{+}$ions to be obtained to within 4ppm.

All compounds tested in biological system were at least 95\% pure as judged by GC/MS and NMR. SQ109 was obtained from MedChem Express (Monmouth Junction, NJ) was at least $98 \%$ as judged by its $1 \mathrm{H}$ NMR certificate of analysis. The molecular weight of SQ109 was further confirmed during metabolism studies.

General procedure for reductive amination reaction. The reaction was conducted according to the procedure described previously by Abdel-Magid et al. ${ }^{2}$. The schematic for synthesis is depicted in Supplemental Figure 1. The diamine was stirred with the 2-adamantanone (9, Supplemental Figure 1) with a 1:2 mole ratio in methanol $(10 \mathrm{ml})$ at room temperature for 24 hours. Afterwards, GC-MS analysis of the reaction mixture revealed the formation of the corresponding di-imine with a minority of the mono-imine. The reaction was 
cooled in an ice bath and excess of $\mathrm{NaBH}_{4}$ (5 equivalents) was slowly added portion-wise to the solution over 5 minutes. The reaction was allowed to warm slowly in the ice bath over 24 hours and then was rotaryevaporated to dryness. Ethyl acetate $(75 \mathrm{ml})$ and water $(10 \mathrm{ml})$ were added to the flask, and the solution was transferred to a separatory funnel and shaken vigorously. The organic layer was separated from the aqueous layer and washed with water $(2 \times 10 \mathrm{ml})$, saturated brine $(10 \mathrm{ml})$, dried over $\mathrm{Na}_{2} \mathrm{SO}_{4}$, filtered, and rotaryevaporated to dryness. The solid was then purified by flash chromatography using first ethyl acetate as eluent and then ethyl acetate/triethylamine at a 9:1 ratio.

$N^{1}$-(adamantan-2-yl)-N²-(adamantan-2-yl)ethane-1,3-diamine (12): Ethylenediamine (10, $\left.120 \mathrm{mg}, 2.0 \mathrm{mmol}\right), 2-$ adamantanone $(9,600 \mathrm{mg}, 4.0 \mathrm{mmol})$, methanol $(10 \mathrm{ml})$, and $\mathrm{NaBH}_{4}(378 \mathrm{mg}, 10 \mathrm{mmol})$ were used to give $641.4 \mathrm{mg}$ of crude product as a white solid. After purification, $225 \mathrm{mg}$ (34\% yield) of pure 12 was obtained as white crystals. GC-MS: $328 \mathrm{M}^{+}, \sim 1 \% ; 164,100 \% .{ }^{1} \mathrm{H}-\mathrm{NMR}: \delta$ 2.72-2.71 (m overlap peak, $\left.6 \mathrm{H}\right), 1.98-1.95$ (m, $4 \mathrm{H}), 1.85(\mathrm{~m}, 10 \mathrm{H}), 1.77(\mathrm{~m}, 2 \mathrm{H}), 1.71-1.68(\mathrm{~m}, 9 \mathrm{H}), 1.51-1.48(\mathrm{~m}, 5 \mathrm{H})$. High-resolution mass spectrum calculated for $\mathrm{C}_{22} \mathrm{H}_{37} \mathrm{~N}_{2}[\mathrm{M}+\mathrm{H}]^{+}=329.2951$, observed for $\mathrm{C}_{22} \mathrm{H}_{37} \mathrm{~N}_{2}[\mathrm{M}+\mathrm{H}]^{+}=329.2960$.

$N^{1}$-(adamantan-2-yl)-N³-(adamantan-2-yl)propane-1,3-diamine (15): 1,3-Diamino-propane (13, 148 mg, 2.0 mmol), 2-adamantanone $(9,600 \mathrm{mg}, 4.0 \mathrm{mmol})$, methanol $(10 \mathrm{ml})$, and $\mathrm{NaBH}_{4}(378 \mathrm{mg}, 10 \mathrm{mmol})$ were used to give $658.2 \mathrm{mg}$ of crude product as a white solid. After purification, $390 \mathrm{mg}$ ( $57 \%$ yield) of pure 15 was obtained as white crystals. GC-MS: $342 \mathrm{M}^{+}, 2 \% ; 150,100 \% .{ }^{1} \mathrm{H}-\mathrm{NMR}: \delta$ 2.74-2.64 (m, 6H), 2.00-1.90 (m, 5H), 1.90-1.79 (m, 11H), 1.76-1.65 (m, 13H), 1.54-1.44 (m, 4H). High-resolution mass spectrum calculated for $\mathrm{C}_{23} \mathrm{H}_{39} \mathrm{~N}_{2}[\mathrm{M}+\mathrm{H}]^{+}=343.3108$, observed for $\mathrm{C}_{23} \mathrm{H}_{39} \mathrm{~N}_{2}[\mathrm{M}+\mathrm{H}]^{+}=343.3118$.

$N^{1}$-(adamantan-2-yl)-N4-(adamantan-2-yl)butane-1,4-diamine (18): 1,4-Diamino-butane (16,176 mg, $\left.2.0 \mathrm{mmol}\right)$, 2-adamantanone $(9,600 \mathrm{mg}, 4.0 \mathrm{mmol})$, methanol $(10 \mathrm{ml})$, and $\mathrm{NaBH}_{4}(378 \mathrm{mg}, 10 \mathrm{mmol})$ were used to give $678.2 \mathrm{mg}$ of crude product as a white solid. After purification, $146 \mathrm{mg}$ ( $21 \%$ yield) of pure 18 was obtained as white crystals. GC-MS: $356 \mathrm{M}^{+}, \sim 1 \% ; 164,100 \%$. ${ }^{1} \mathrm{H}-\mathrm{NMR}: \delta$ 2.74-2.67 (m, 2H), 2.66-2.57 (m, 4H), $2.00-1.89$ 
$(\mathrm{m}, 4 \mathrm{H}), 1.86-1.80(\mathrm{~m}, 10 \mathrm{H}), 1.77-1.65(\mathrm{~m}, 10 \mathrm{H}), 1.62-1.38(\mathrm{~m}, 10 \mathrm{H})$. High-resolution mass spectrum calculated for $\mathrm{C}_{24} \mathrm{H}_{41} \mathrm{~N}_{2}[\mathrm{M}+\mathrm{H}]^{+}=357.3264$, observed for $\mathrm{C}_{24} \mathrm{H}_{41} \mathrm{~N}_{2}[\mathrm{M}+\mathrm{H}]^{+}=357.3272$.

$N^{1}$-(adamantan-2-yl)- $N^{5}$-(adamantan-2-yl)pentane-1,5-diamine (21): 1,5-Diamin-pentane (20, 225 mg, 2.2 mmol), 2-adamantanone (9,600 mg, $4.0 \mathrm{mmol})$, Methanol $(10 \mathrm{ml})$, and $\mathrm{NaBH}_{4}(378 \mathrm{mg}, 10 \mathrm{mmol})$ were used to give a white solid. After purification, $451 \mathrm{mg}$ (61\% yield) of pure $\mathbf{2 1}$ was obtained as white crystals. GC-MS: $370 \mathrm{M}^{+}$2\%; 164, 100\%. ' H-NMR: $\delta 2.70(\mathrm{~s}, 2 \mathrm{H}), 2.59(\mathrm{t}, \mathrm{J}=7.2 \mathrm{~Hz}, 4 \mathrm{H}), 1.97-1.89(\mathrm{~m}, 4 \mathrm{H}), 1.89-1.81(\mathrm{~m}$, $10 \mathrm{H}), 1.77-1.66(\mathrm{~m}, 10 \mathrm{H}), 1.55-1.44(\mathrm{~m}, 8 \mathrm{H}), 1.44-1.28(\mathrm{~m}, 3 \mathrm{H})$. High-resolution mass spectrum calculated for $\mathrm{C}_{25} \mathrm{H}_{43} \mathrm{~N}_{2}[\mathrm{M}+\mathrm{H}]^{+}=371.3421$, observed for $\mathrm{C}_{25} \mathrm{H}_{43} \mathrm{~N}_{2}[\mathrm{M}+\mathrm{H}]^{+}=371.3421$.

$N^{1}$-(adamantan-2-yl)- $N^{2}$-(adamantan-2-yl)cyclohexane-1,2-diamine (24): Cyclohexane-1,2-diamine (as a racemic mixture) $(22,228 \mathrm{mg}, 2.0 \mathrm{mmol}), 2$-adamantanone $(9,600 \mathrm{mg}, 4.0 \mathrm{mmol})$, methanol (10 $\mathrm{ml})$, and $\mathrm{NaBH}_{4}(378 \mathrm{mg}, 10 \mathrm{mmol}$ ) were used to give $740 \mathrm{mg}$ of crude product as a white solid. After purification, 440 mg (58\% yield) of pure 24 was obtained as white solid. GC-MS: $382 \mathrm{M}+, 4 \% ; 151,100 \% .{ }^{1} \mathrm{H}-\mathrm{NMR}: \delta 2.86-$ $2.70(\mathrm{~m}, 2 \mathrm{H}), 2.25-1.59(\mathrm{~m}, 33 \mathrm{H}), 1.55-1.44(\mathrm{~m}, 4 \mathrm{H}), 1.28-1.15(\mathrm{~m}, 2 \mathrm{H}), 1.00-0.89(\mathrm{~m}, 2 \mathrm{H})$. High-resolution mass spectrum calculated for $\mathrm{C}_{26} \mathrm{H}_{43} \mathrm{~N}_{2}[\mathrm{M}+\mathrm{H}]^{+}=383.3421$, observed for $\mathrm{C}_{26} \mathrm{H}_{43} \mathrm{~N}_{2}[\mathrm{M}+\mathrm{H}]^{+}=383.3424$.

$N^{1}$-(adamantan-2-yl)-N²-(adamantan-2-yl) (1R,2R) cyclohexane-1,2-diamine (27): (1R,2R)-cyclohexane-1,2 diamine (1,2 trans configuration) $(25,228 \mathrm{mg}, 2.0 \mathrm{mmol}), 2$-adamantanone $(9,600 \mathrm{mg}, 4.0 \mathrm{mmol})$, methanol (10 ml), and $\mathrm{NaBH}_{4}(378 \mathrm{mg}, 10 \mathrm{mmol})$ were used to give $793 \mathrm{mg}$ of crude product as a white solid. After purification, $315 \mathrm{mg}$ (41\% yield) of pure 27 was obtained as a yellowish solid. GC-MS: 382, M+ 1\%; 150, 100\%. ${ }^{1} \mathrm{H}-\mathrm{NMR}: \delta$ 2.85-2.83 (m, 2H), 2.24-1.62 (m, 34H), 1.53-1.45 (m, 4H), 1.27-1.15 (m, 2H), 0.98-0.89 (m, $2 \mathrm{H})$. High-resolution mass spectrum calculated for $\mathrm{C}_{26} \mathrm{H}_{43} \mathrm{~N}_{2}[\mathrm{M}+\mathrm{H}]^{+}=383.3421$, observed for $\mathrm{C}_{26} \mathrm{H}_{43} \mathrm{~N}_{2}[\mathrm{M}+\mathrm{H}]^{+}$ $=383.3421$.

$N^{1}$-(adamantan-2-yl)-N $N^{3}$-(adamantan-2-yl)-2,2-dimethylpropane-1,3-diamine (30): 2,2-Dimethyl-1,3 propane diamine (28, $204 \mathrm{mg}, 2.0 \mathrm{mmol})$, 2-adamantanone (9, $600 \mathrm{mg}, 4.0 \mathrm{mmol})$, methanol (10 ml), and $\mathrm{NaBH}_{4}(378$ 
$\mathrm{mg}, 10 \mathrm{mmol}$ ) were used to give $677 \mathrm{mg}$ of crude product as an oily solid. After purification, $227 \mathrm{mg}(31 \%$ yield) of pure 30 was obtained as yellowish solid. GC-MS: $370, \mathrm{M}+\sim 1 \% ; 204,100 \% .{ }^{1} \mathrm{H}-\mathrm{NMR}(400 \mathrm{MHz}$; $\left.\mathrm{CDCl}_{3}\right): \delta 2.53(\mathrm{~s}, 2 \mathrm{H}), 2.34-2.31(\mathrm{~m}, 4 \mathrm{H}), 1.95-1.92(\mathrm{~m}, 4 \mathrm{H}), 1.76-1.58(\mathrm{~m}, 2 \mathrm{H}), 1.39-1.34(\mathrm{~m}, 4 \mathrm{H}), 1.15-1.08$ $(\mathrm{m}, 2 \mathrm{H}), 0.84-0.82(\mathrm{~m}, 6 \mathrm{H})$. High-resolution mass spectrum calculated for $\mathrm{C}_{25} \mathrm{H}_{43} \mathrm{~N}_{2}[\mathrm{M}+\mathrm{H}]^{+}=371.3424$, observed for $\mathrm{C}_{25} \mathrm{H}_{43} \mathrm{~N}_{2}[\mathrm{M}+\mathrm{H}]^{+}=383.3421$.

1-methyl-4-(4-(trifluoromethoxy)phenoxy)benzene (33): To a mixture of p-bromotoluene (31, $48.2 \mathrm{~g}, 0.28 \mathrm{~mol})$, 4-(trifluoro-methoxy)phenol $(32,50.0 \mathrm{~g}, 0.28 \mathrm{~mol}), 200 \mathrm{ml}$ of dimethylformamide (DMF) and $2.0 \mathrm{~g}$ of $\mathrm{Cu}$ powder, was added in small portions $5 \mathrm{~g}$ of sodium hydride $(\mathrm{NaH}) 60 \%$ dispersion in mineral oil with vigorous stirring. The mixture was heated at $170{ }^{\circ} \mathrm{C}$ with vigorous stirring for 2 days. GC-MS indicated that the reaction was not completed and that the copper powder had been consumed. Then $1.4 \mathrm{~g}$ of Cu powder was added and 12 hours later another portion of $1.0 \mathrm{~g}$ of $\mathrm{Cu}$ powder was added. After $24 \mathrm{~h}$ later, another portion of $6.2 \mathrm{~g}$ of $\mathrm{Cu}$ was added together with $1.0 \mathrm{~g}$ of $60 \% \mathrm{NaH}$. The addition of $\mathrm{NaH}$ was done slowly. After stirring for 24 more hours at $170{ }^{\circ} \mathrm{C}$ the reaction was sufficiently close to completion as judged by GC-MS and was stopped. The crude dark brown mixture was filtered through a Celite filter $(8 \mathrm{~cm}(\mathrm{w}) \times 7 \mathrm{~cm}(\mathrm{~h}))$ and rinsed with $200 \mathrm{~mL}$ of DMF. The solvent and all unreacted starting materials were removed on a rotary evaporator. To the residue was added $400 \mathrm{ml}$ of hexane, and after stirring, the supernatant was decanted off from the tar that had separated. This tarry remainder was extracted once with $200 \mathrm{ml}$ of hexane. The combined hexane extracts were passed through a Celite filter $(8 \mathrm{~cm}(\mathrm{w}) \times 2 \mathrm{~cm}(\mathrm{~h}))$, rinsed with $200 \mathrm{~mL}$ of hexane, the solvent was rotaryevaporated and the crude product was passed through a short column of silica gel $(10 \mathrm{~cm}(\mathrm{~h}) \times 7 \mathrm{~cm}(\mathrm{w}))$ eluting with hexane. Removal of the solvent by rotary evaporation afforded $45.0 \mathrm{~g}$ ( $60 \%$ yield) of the desired product 33 as a pale-beige oil. The product is pure by GC-MS and NMR. GC-MS: M $^{+}=268(100 \%)$; ${ }^{1} \mathrm{H}$ NMR $\left(400 \mathrm{MHz}, \mathrm{CDCl}_{3}\right): \delta=6.90-6.95(\mathrm{~m}, 4 \mathrm{H}) ; 7.12-7.18(\mathrm{~m}, 4 \mathrm{H}) ; 2.3(\mathrm{~s}, 3 \mathrm{H}) .{ }^{19} \mathrm{~F}$ decoupled NMR $(400$ $\left.\mathrm{MHz}, \mathrm{CDCl}_{3}\right): \delta=-58(\mathrm{~s})$ 
1-(bromomethyl)-4-(4-(trifluoromethoxy)phenoxy)benzene (34): A solution of 33 (2.68 g, $10.0 \mathrm{mmol})$, NBS

$(2.14 \mathrm{~g}, 12.0 \mathrm{mmol})$ and $30 \mathrm{mg}$ of benzoyl peroxide in $60 \mathrm{~mL}$ of carbon tetrachloride was refluxed for 16 hours.

The resulting suspension was filtered through celite and the solvent was rotary-evaporated to give $3.58 \mathrm{~g}$ of the desired product 34 as a yellow oil. GC-MS revealed no more starting material and that it was of sufficient purity for use in the next step.

$N^{1}$-(4-(4-(trifluoromethoxy)phenoxy)benzyl)ethane-1,2-diamine (35): Following the procedure of Onajole et al. ${ }^{3}$, to a cool solution (in dry ice acetone) of ethylene diamine $(10,17.3 \mathrm{~g}, 288 \mathrm{mmol}$ ) in $200 \mathrm{~mL}$ of methylene chloride was added dropwise over 3 hours to a solution of 34 (2.0 g, 5.76 mmol assuming that 34 was $100 \%$ pure) in $100 \mathrm{~mL}$ of methylene chloride. Then the solution was allowed to warm slowly to room temperature and GC-MS showed no more starting material 34. The solution was then rotary-evaporated to eliminate most of the excess of ethylene diamine. The resulting orange oil was taken up with $60 \mathrm{~mL}$ of methylene chloride, then washed with water $(3 \times 10 \mathrm{~mL})$, brine $(10 \mathrm{~mL})$, dried over $\mathrm{Na}_{2} \mathrm{SO}_{4}$, filtered and rotary-evaporated to afford $1.94 \mathrm{~g}$ of yellow oil. Then $10 \%$ aqueous solution of $\mathrm{HCl}(20 \mathrm{~mL})$ was added resulting in the formation of a white precipitate, which was filtered, and dried to give $822 \mathrm{mg}$ of a white solid. This was then dissolved in 10 $\mathrm{mL}$ of $10 \%$ sodium hydroxide and extracted with methylene chloride $(3 \times 10 \mathrm{~mL})$. The combined organic layer was washed with brine $(10 \mathrm{~mL})$, dried over $\mathrm{Na}_{2} \mathrm{SO}_{4}$, filtered and rotary-evaporated to afford $714 \mathrm{mg}$ of the desired aryl ether diamine 33 as a yellow oil. GC-MS showed a major peak $\mathrm{M}+=326, \sim 1 \% ; 267,100 \%$ and a minor peak with $\mathrm{M}+=590, \sim 1 \% ; 267,100 \%$. The product was estimated to be about $90 \%$ pure by GC-MS. ${ }^{1} \mathrm{H}-$ $\operatorname{NMR}\left(400 \mathrm{MHz} ; \mathrm{CDCl}_{3}\right):=$ 7.34-7.30 (m, 2H), 7.18-7.15 (m, 2H), 7.00-6.96 (m, 4H), 3.79 (s, 2H), 2.85-2.82 (m, $2 \mathrm{H}), 2.73-2.70(\mathrm{~m}, 2 \mathrm{H})$. This material was used without further purification in the next step.

$N^{1}$-adamantan-2-yl-N²-(4-(4-(trifluoromethoxy)phenoxy)benzyl)ethane-1,2-diamine (8) (TBL-140): The solution of the aryl ether diamine 35 (600 mg, $1.84 \mathrm{mmol}$, assuming that $35100 \%$ was pure) and 2-adamantanone (9, $304 \mathrm{mg}, 2.02 \mathrm{mmol}$ ) in $10 \mathrm{~mL}$ of dry methanol was stirred at room temperature for 24 hours. GC-MS showed clean formation of the 2-adamantanone imine of the aryl ether. Then the solution was cooled in an ice bath and $\mathrm{NaBH}_{4}(699 \mathrm{mg}, 18.4 \mathrm{mmol})$ was added portion wide over a period of 5 minutes. The solution was then 
allowed to warm up slowly (in the ice bath) to room temperature and stirred for 48 hours. GC-MS revealed the completed reduction of the imine to give the desired product 8 . Then $1 \mathrm{~mL}$ of water was added and the solution was rotary-evaporated to dryness. The resulting white solid was suspended and shaked vigorously in $50 \mathrm{~mL}$ of ethyl acetate and $20 \mathrm{ml}$ of water. The organic layer was separated and the aqueous layer was extracted with ethyl acetate $(3 \times 10 \mathrm{~mL})$. The combined organic layers were washed with water $(20 \mathrm{~mL})$, brine $(20 \mathrm{~mL})$, dried over $\mathrm{Na}_{2} \mathrm{SO}_{4}$, filtered and rotary-evaporated to give $840 \mathrm{mg}$ of white oily solid. This crude product was further purified by flash chromatography over silica gel using 9.9/0.1 ratio ethyl acetate/triethylamine (9/1) and methanol to give $600 \mathrm{mg}(71 \%$ yield) of the desired product 8 (TBL-140) as a white oil which solidified as a white powder while standing at room temperature. GC-MS showed a major peak $\mathrm{M}+=460, \sim 1 \% ; 164,100 \%$. ${ }^{1} \mathrm{H}-\mathrm{NMR}\left(400 \mathrm{MHz} ; \mathrm{CDCl}_{3}\right):=7.33-7.30(\mathrm{~m}, 2 \mathrm{H}), 7.18-7.15(\mathrm{~m}, 2 \mathrm{H}), 6.99-6.96(\mathrm{~m}, 4 \mathrm{H}), 3.79(\mathrm{~s}, 2 \mathrm{H}), 2.76$ (quintet, $J=2.0 \mathrm{~Hz}, 4 \mathrm{H}), 2.69(\mathrm{~s}, 1 \mathrm{H}), 1.97-1.48(\mathrm{~m}, 18 \mathrm{H}$ including $\mathrm{H}$ derived from residual water in the solvent). High-resolution mass spectrum calculated for $\mathrm{C}_{26} \mathrm{H}_{31} \mathrm{O}_{2} \mathrm{~N}_{2} \mathrm{~F}_{3}[\mathrm{M}+\mathrm{H}]^{+}=461.2421$ observed for $\mathrm{C}_{26} \mathrm{H}_{31} \mathrm{O}_{2} \mathrm{~N}_{2} \mathrm{~F}_{3}[\mathrm{M}+\mathrm{H}]^{+}=461.2410$. 
Table S1 - MICs of bis-adamantyl derivatives and TBL-140 against Mtb H37Rv

\begin{tabular}{|c|c|c|}
\hline Compound & Chemical Structure & $\begin{array}{c}\text { Minimum } \\
\text { Inhibitory } \\
\text { Concentration } \\
\text { (MIC), } \mu \mathrm{g} / \mathrm{mL}\end{array}$ \\
\hline 12 & & 3.3 \\
\hline 15 & & $>55$ \\
\hline 18 & & $>57$ \\
\hline 21 & & $>59$ \\
\hline 24 & & 7.7 \\
\hline 27 & & 7.7 \\
\hline 30 & & 15 \\
\hline 8 & & 1.2 \\
\hline
\end{tabular}


Figure S1 - Synthesis scheme for the different di-adamantane amines. These compounds were synthesized by reductive amination of 2-adamantanone (9) with the corresponding diamine according to method described by Abdel-Magid et. al. ${ }^{2}$.

$\overbrace{}^{\mathrm{O}}+\mathrm{H}_{2} \mathrm{~N}_{\mathrm{n}}^{\mathrm{N}} \mathrm{NH}_{2} \stackrel{\mathrm{MeOH}}{\longrightarrow}$

9

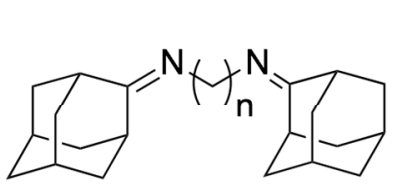

$$
\begin{aligned}
& n=2,11 \\
& n=3,14 \\
& n=4,17 \\
& n=5,20
\end{aligned}
$$

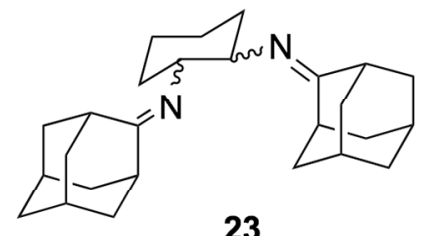

23

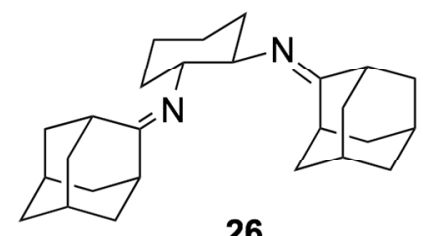

26<smiles>CC(C)(CN)CN</smiles>

28<smiles>CC(C)(CN=C1C2CC3CC(C2)CC1C3)CN=C1C2CC3CC(C2)CC1C3</smiles>

29

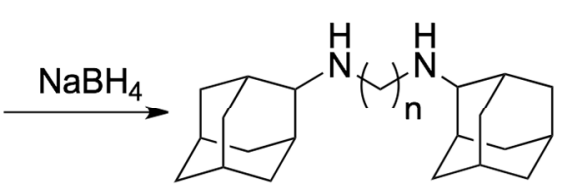

$$
\begin{aligned}
& n=2,12 \\
& n=3,15 \\
& n=4,18 \\
& n=5,21
\end{aligned}
$$

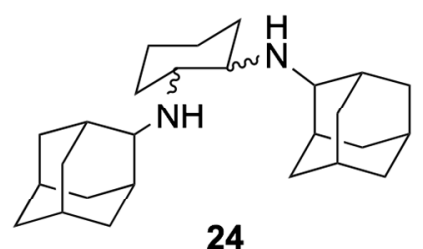

24<smiles>C1CCC(NC2C3CC4CC(C3)CC2C4)C(NC2C3CC4CC(C3)CC2C4)C1</smiles>

27<smiles>CC(C)(CNC1C2CC3CC(C2)CC1C3)CNC1C2CC3CC(C2)CC1C3</smiles>

30 
Figure S2 - Synthesis scheme for $N^{1}$-adamantan-2-yl- $N^{2}-(4-(4-$

(trifluoromethoxy)phenoxy)benzyl)ethane-1,2-diamine 8 (TBL-140). The first step involved coupling of para-bromo-toluene (31) with 4-trifluoromethoxy phenol (32) in the presence of copper powder and sodium hydride according to the procedure of Nilsen et al. ${ }^{4}$ to give the diaryl ether (33) in $60 \%$ yield. Bromination of 33 with N-bromosuccinimide (NBS) followed by coupling in the presence of an excess of ethylene diamine according to the procedure of Onajole et al. ${ }^{3}$ gave the mono substituted ethylene diamine aryl ether 35 . The final step involved reductive amination of 35 with $9{ }^{2}$ and $\mathrm{NaBH}_{4}$ to afford the desired compound TBL-140 (8) in $71 \%$ yield after flash chromatography as a white oil which solidified as a white powder upon standing at room temperature.

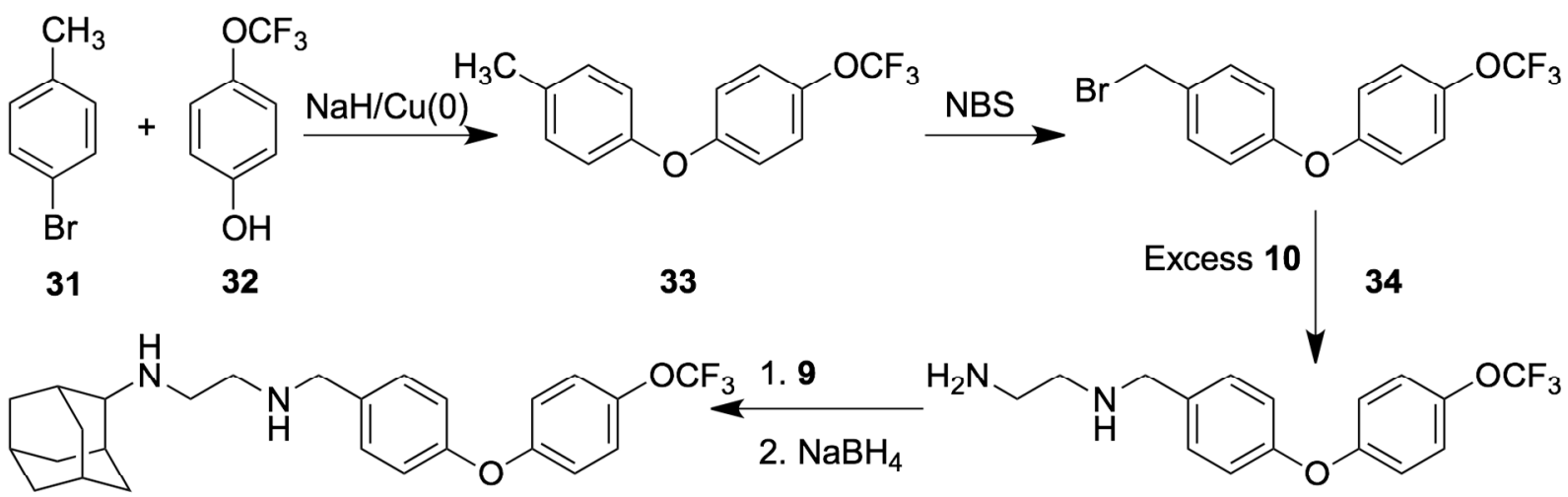

(TBL-140) 
Figure S3 - Ramachandran plot of MmpL3 structure model. Ramachandran plot analysis was performed using the RAMPAGE server tool. For the MmpL3 transmembrane region (residues 1-728) shown in Figure 5 , the number of residues in favored regions is $91.3 \%$, allowed regions is $4.8 \%$, and outlier regions is $3.8 \%$.
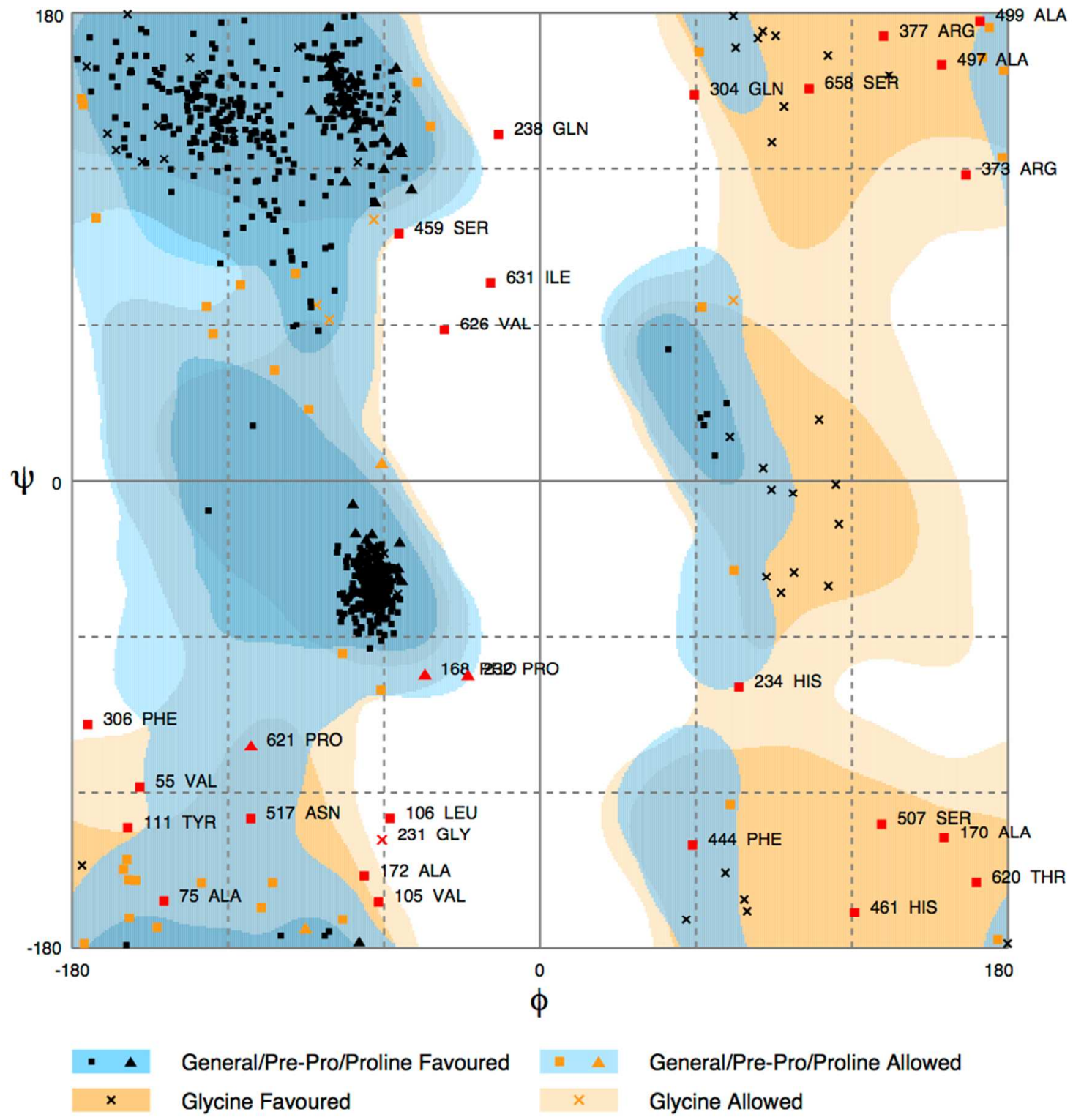

\footnotetext{
Number of residues in favoured region ( $-98.0 \%$ expected) : $875(92.9 \%)$

Number of residues in allowed region ( 2.0\% expected) : $39(4.1 \%)$

Number of residues in outlier region

: $28(3.0 \%)$
} 
Figure S4 - Effect of SQ109 on $\Delta \Psi$ and $\Delta \mathrm{pH}$ in $\boldsymbol{M}$. bovis BCG. We measured the $\Delta \Psi$ and $\Delta \mathrm{pH}$ by labeling mycobacteria with $\mathrm{DiOC}_{2}$ and CMFDA, respectively. We maintained the $(\mathrm{v} / \mathrm{v}) \% \mathrm{DMSO}$ in solvent controls at $1 \%$ or less as needed to match the highest required for compound treatment. We added compound treatment at the indicated multiples of their in vitro MIC.
A) Effect of SQ109 on $\Delta \Psi$ in M. bovis BCG
B) Effect of SQ109 on $\triangle \mathrm{pH}$ in M. bovis BCG

a

b
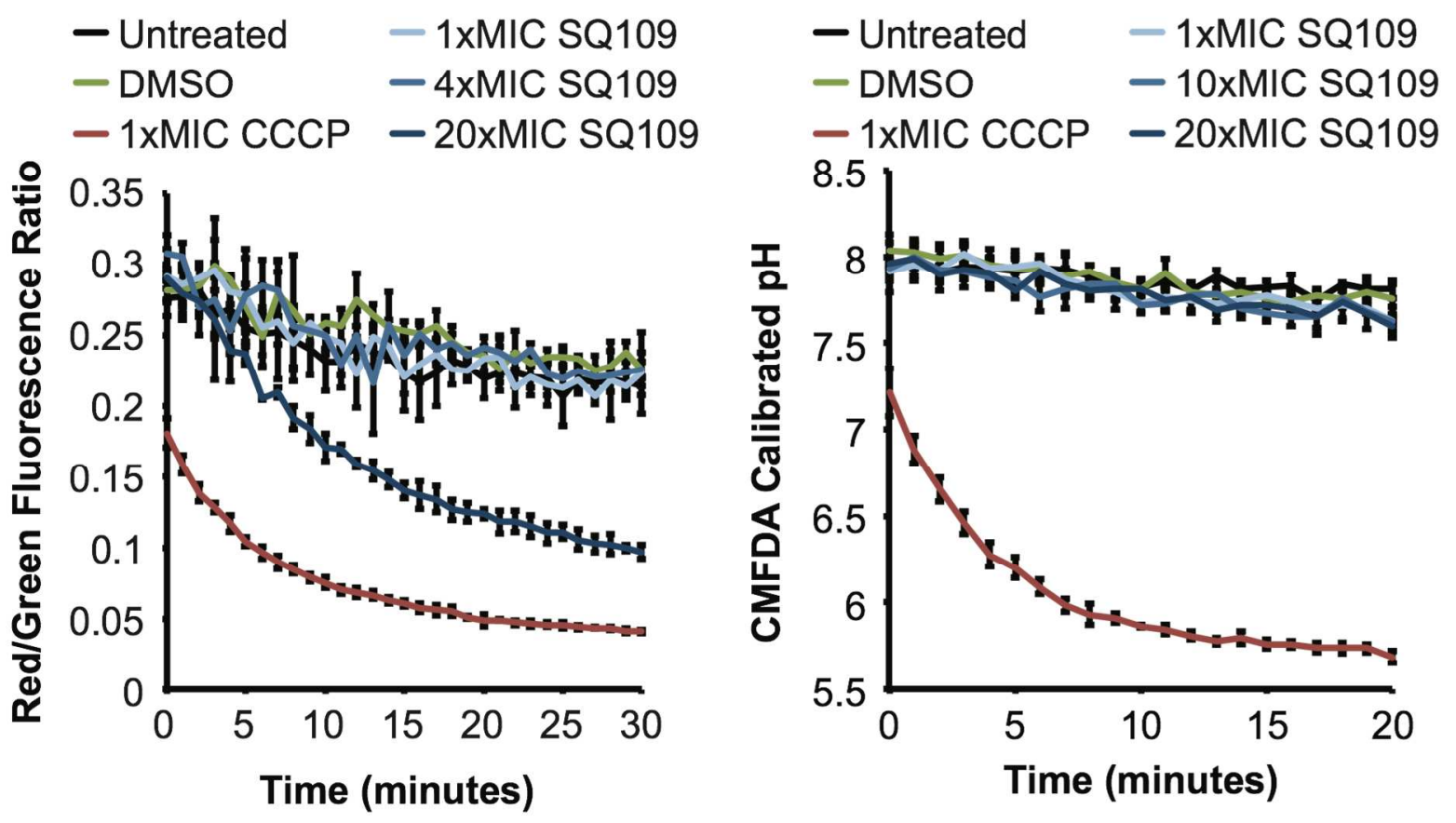


\section{References}

(1) Armarego, F. W. L. Purification of Laboratory Chemicals, 7 ed.; Armarego, F. W. L., Lin Chai, C. L., Eds.; Elsevier: Oxford, United Kingdom, 2013.

(2) Abdel-Magid, A. F.; Carson, K. G.; Harris, B. D.; Maryanoff, C. A.; Shah, R. D. Reductive Amination of Aldehydes and Ketones with Sodium Triacetoxyborohydride. Studies on Direct and Indirect Reductive Amination Procedures. J. Org. Chem. 1996, 61 (11), 3849-3862.

(3) Onajole, O. K.; Sosibo, S.; Govender, P.; Govender, T.; van Helden, P. D.; Maguire, G. E. M.; MlinarićMajerski, K.; Wiid, I.; Kruger, H. G. Novel linear diamine disubstituted polycyclic "cage" derivatives as potential antimycobacterial candidates. Chem Biol Drug Design 2011, 78 (6), 1022-1030 DOI: 10.1111/j.1747-0285.2011.01242.x.

(4) Nilsen, A.; Miley, G. P.; Forquer, I. P.; Mather, M. W.; Katneni, K.; Li, Y.; Pou, S.; Pershing, A. M.; Stickles, A. M.; Ryan, E.; et al. Discovery, Synthesis, and Optimization of Antimalarial 4(1 H)-Quinolone3-Diarylethers. J. Med. Chem. 2014, 57 (9), 3818-3834 DOI: 10.1021/jm500147k. 